\title{
ANNULAR PERIPHERAL RETINAL DETACHMENT ASSOCIATED WITH VITREOUS CONDENSATION*
}

\author{
BY \\ R. PITTS CRICK AND J. J. BLAKE \\ London
}

VERY occasionally, in the course of deep anterior scleral inflammation, an irregular peripheral ring of retinal detachment can be seen, presumably exudative in origin, which subsides spontaneously after giving rise to apprehension and a prolonged search for a non-existent retinal hole. Stallard (1954) has reported six patients with annular peripheral retinal detachment, in three of whom the condition was bilateral. A definite aetiology could not be ascribed to any of the cases. Three recovered after surgical treatment and one spontaneously.

Recently a patient was observed with a similar condition and her case is here described as the findings pointed to a definite local cause.

\section{Case Report}

A married woman aged 67 years first attended the Royal Eye Hospital on April 23, 1958, complaining of a fairly sudden onset of blurred vision 3 weeks previously. The visual acuity in the right eye was $6 / 18$ (with $+0.75 \mathrm{D}$ sph. 6/6) and in the left it was $6 / 36$ (with $+1.25 \mathrm{D}$ sph. 6/36).

Examination.-The right eye was normal.

The left eye showed dense vitreous opacities with a condensation ring where the contracted vitreous had become drawn forward from its attachment around the margin of the optic disc. A sausage-like ring of retinal detachment could be seen all round the periphery, though varying a little in extent. It trans-illuminated easily and did not have the appearance of a choroidal detachment. In the course of careful ophthalmoscopic search under extreme mydriasis no retinal hole could be found, but this examination showed strands of vitreous radiating outwards to the summit of the roll of detachment and this was confirmed by slit-lamp microscopy. It would appear that the detachment of the retina at its periphery was due to the traction of the shrinking vitreous (Figure, opposite).

Mild anterior uveitis was revealed by the presence of a flare and cells in the anterior chamber. The ocular tension was normal.

The patient had a history of pulmonary tuberculosis discovered after a haemoptysis in December, 1957, and was under treatment at a chest clinic. General medical investigations were carried out in case they pointed to possible foci of sepsis or allergens which could be held responsible for the uveitis and for causing biochemical changes in the

$$
\text { * Received for pubiication June, 19, } 1961 .
$$




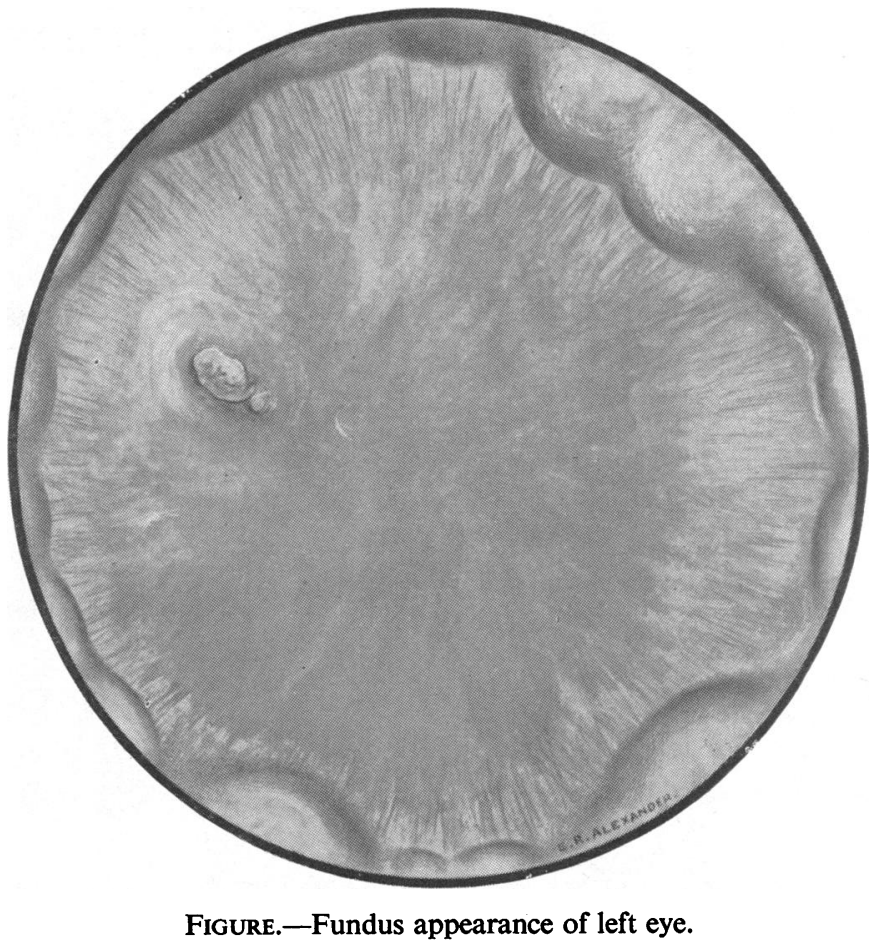

vitreous. Physical examination revealed only signs of emphysema and some degree of hypertension (blood pressure 200/105). A chest $x$ ray showed mottling and linear opacities in both upper zones consistent with fibrosis and infiltration. Sinus $x$ rays showed a probable fluid level in the left maxillary antrum, which was confirmed by tilting. The Wassermann reaction was negative. The erythrocyte sedimentation rate was $27 \mathrm{~mm}$. in the first hour. The red blood count was $4,500,000 / \mathrm{cu}$. mm., $\mathrm{Hb} 92$ per cent. (Haldane). The white blood count was 11,700; neutrophils 64 per cent, lymphocytes 32 per cent., monocytes 4 per cent. Serum proteins total $6.8 \mathrm{~g} . / 100 \mathrm{ml}$. (Albumin $4 \cdot 3$, globulin $2 \cdot 52 \mathrm{~g} . / 100 \mathrm{ml}$.); albumin/globulin ratio $1 \cdot 7: 1$.

Treatment.-The uveitis was treated locally with hydrocortisone and mydriatics and gradually subsided, no cells being visible in the anterior chamber after the first 4 months, after which all treatment was discontinued.

Result.-The vitreous became a little clearer and 16 months from the onset a few leashes of new vessel formation appeared on the posterior face of the vitreous condensation and the anterior vitreous face had fallen back about $2 \mathrm{~mm}$. behind the posterior surface of the lens. The retinal appearance was unchanged.

There was no change in the condition 2 years after the onset and $\mathrm{Mr}$. $\mathrm{H}$. B. Stallard kindly saw the patient at this time. He considered the condition to be due to mild uveitis with exudation of inflammatory fluid.

Progress.-Now, 3 years after the patient's first attendance, the visual acuity of the left eye is $6 / 60$ and there is no change in the ring-like detachment with its attachment to the vitreous condensation and still no evidence of active uveitis. 
It seems reasonable to conclude that the annular elevation of the peripheral retina, though partly due to mild inflammatory exudation, was partly caused by centripetal traction of the condensed vitreous by which it has subsequently been maintained.

\section{Summary}

A case of peripheral annular retinal detachment is described. It is concluded that the condition and its persistence was mainly due to centripetal traction of the condensed vitreous.

We wish to thank Mr. H. B. Stallard for kindly seeing the patient and Dr. Mary Holt, Physician to the Royal Eye Hospital for advice on the medical condition.

\section{REFERENCE}

Stallard, H. B. (1954). Brit. J. Ophthal., 38, 115. 